\title{
Article \\ Comparison of Salt-Related Knowledge and Behaviors Status of WeChat Users between 2019 and 2020
}

\author{
Yibing Yang ${ }^{1}$, Jinglei Wang ${ }^{1}$, Jixiang $\mathrm{Ma}^{2}$, Wenhui Shi ${ }^{1, *}$ and Jing $\mathrm{Wu}^{3, *}$ \\ 1 Office of Non-Communicable Disease and Aging Health Management, Chinese Center for Disease Control \\ and Prevention, Beijing 102206, China; yangyb@chinacdc.cn (Y.Y.); wangj1100@chinacdc.cn (J.W.) \\ 2 Shandong Center for Disease Control and Prevention, Jinan 250014, China; majix@163.com \\ 3 National Center for Chronic and Noncommunicable Disease Control and Prevention, Chinese Center for \\ Disease Control and Prevention, Beijing 100050, China \\ * Correspondence: shiwh@chinacdc.cn (W.S.); wujing@ncncd.chinacdc.cn (J.W.)
}

Citation: Yang, Y.; Wang, J.; Ma, J.; Shi, W.; Wu, J. Comparison of Salt-Related Knowledge and Behaviors Status of WeChat Users between 2019 and 2020. Nutrients 2021, 13, 2141. https://doi.org/ 10.3390/nu13072141

Academic Editor: Jose Lara

Received: 7 May 2021

Accepted: 21 June 2021

Published: 22 June 2021

Publisher's Note: MDPI stays neutral with regard to jurisdictional claims in published maps and institutional affiliations.

Copyright: (c) 2021 by the authors. Licensee MDPI, Basel, Switzerland. This article is an open access article distributed under the terms and conditions of the Creative Commons Attribution (CC BY) license (https:// creativecommons.org/licenses/by/ $4.0 /)$.

\begin{abstract}
In order to identify the status of salt-related knowledge and behavior of the residents who were active in WeChat software between 2019 and 2020, 10-day salt-related surveys were conducted in 2019 and 2020 based on the WeChat public platform of China Healthy Lifestyle for All Campaign. Distribution and scores of salt-related knowledge, salt reduction behavior and highsalt intake behavior between 2019 and 2020 were compared. Data of 2109 participants in 2019 and 12,732 participants in 2020 were left for analysis. Overall, $88.2 \%$ of participants in 2019 had a willingness to reduce the amount of cooking salt in their households, significantly lower than $90.2 \%$ in 2020 ( $p$-value $<0.05$ ). In 2019 and 2020, over $80 \%$ of the participants knew fine dried noodles contain salt, but less than $30 \%$ knew ice cream contains salt. Over $78 \%$ of participants chose $5 \mathrm{~g}$ or $6 \mathrm{~g}$ for the maximum daily salt intake of healthy adults, and about $98 \%$ of participants knew that excessive salt intake would increase the risk of hypertension in both years. The percentage of participants who used salt measuring spoons asked restaurants to use less salt, read the sodium content on the nutrition facts table, chose foods with low sodium content and regularly used low-sodium salt, were $36.1 \%, 45.0 \%, 44.1 \%, 40.3 \%$ and $35.8 \%$ in 2019 , and the percentage increased significantly to $46.4 \%, 49.2 \%, 50.8 \%, 47.1 \%$ and $43.4 \%$ in 2020 (all $p$-value < 0.05 ). The percentage of people regularly eating pickled mustard tubers, salted vegetables and sauce foods or using high-salt condiments also increased from 2019 to 2020 . The median of salt-related knowledge scores, salt reduction behavior scores and high-salt intake behavior scores were 11, 2, 5 points in 2019, and 10, 3, 5 points in 2020, respectively. Compared to 2019, the salt-related knowledge score was relatively lower, while the salt reduction behavior score and high-salt intake behavior score were relatively higher in 2020. Besides, the score of salt-related knowledge and behaviors differed in different gender, age and hypertension groups. The COVID-19 epidemic may have influenced the salt-related knowledge and behaviors status of WeChat users in China. Promotion and education of salt-related knowledge and online behavior intervention are still needed, particularly for male and hypertension patients in the future.
\end{abstract}

Keywords: salt reduction; salt-related knowledge; high salt intake; China Healthy Lifestyle for All

\section{Introduction}

Non-communicable diseases have become a huge threat to the lives and health of the global public; the onset and long-term treatment of chronic diseases will not only reduce the quality of life of the patients and their families but also cause society to rapidly increase in huge expenditures and bear heavy burdens [1-3]. Ischemic heart disease and stroke had become the top-ranked causes of disability adjusted life years(DALYs) in both the 50-74-year and 75-years-and-older age groups across the world, and it was estimated that hypertension and cardiovascular diseases accounted for more than $40 \%$ of all deaths in China and were the main causes of all deaths [2,4]. The excessive intake of salt may increase the risk of hypertension, cardiovascular disease and stroke [5-7]. Over 
3 million deaths worldwide were related to a diet high in sodium in 2017 [8]. Reducing salt intake has been identified as one of the most cost-effective measures countries can take to improve population health outcomes, and if the global salt consumption was reduced to the recommended level, millions of deaths could be prevented [9]. However, the salt intakes of residents of China were still very high, the average salt intake was $9.3 \mathrm{~g} /$ day from the latest report [10], and the average sodium intake was $4318.1 \pm 1814.1 \mathrm{mg} / \mathrm{d}$ (equivalent to $11.0 \pm 4.6 \mathrm{~g} /$ day of salt) in six provinces of the Action on Salt China in 2018 [11], which were both higher than the recommended maximum level of intake by WHO (5 g/day) [12] and Chinese Nutrition Society (6 g/day) [13].

In order to raise public awareness of salt reduction and promote salt reduction behaviors, many action plans and studies had been launched in the mainland of China in the past few decades [11,14-16]. China Healthy Lifestyle for All Campaign (CHLA) was initiated in 2007; CHLA stage one was from 2007 to 2015 with the theme, "Harmonious life, and healthy Chinese people", and all kinds of easy-to-use health support tools such as a salt-restricted spoon, oil control pot and body mass index calculation ruler were developed and promoted [17]. In stage two (2017-2025), the content of CHLA was further expanded. "Three reduction, three healthy" actions including salt reduction, oil reduction, sugar reduction, healthy oral cavity, healthy weight and healthy bones was the first action of CHLA. Salt-reduction-related promotional materials such as audio, video, poster and graphics context materials were developed by the national action office of the CHLA in the past few years and promoted to the whole country for online and offline health education activities. A salt-reduction-related conference was held and an initiative was released [18]. A previous study had found that participants in "CHLA intervention" counties were more likely to know the limits of salt and were more intent to modify their salt consumption [19].

Education on salt-related knowledge and how to reduce salt intake could reduce $24 \mathrm{~h}$ urinary sodium of children and their families from the School-EduSalt study, and better diet-related knowledge, attitudes and behaviors were associated with higher health status $[16,20]$. However, behavior change is complex, long-term and slow; understanding the current population statuses of salt-related knowledge, attitudes and behaviors are essential for further salt-reduction actions [21], and similar studies had been conducted in Australia, America and other countries [22-26]. Salt-related knowledge and behaviors of Chinese residents in 2015 were explored in a previous study [27], based on the data of data from the China Chronic Diseases and Nutrition Surveillance system, and low awareness rate of maximum daily salt intake and the behavior rate of salt reduction of Chinese adult residents were found. However, in recent years, much more activities in the publicity and advocacy of salt reduction have been carried out by the National Health Commission of China, the World Health Organization, the national action office of CHLA and other institutions [18,28-30]. In 2019, the Bureau of Disease Control and Prevention of the National Health Commission launched the "9.15" Salt Reduction Publicity Week, and all regions of the country actively responded and carried out a large number of salt-reduction-related activities [28]. Besides, the unexpected coronavirus disease 2019 (COVID-19) epidemic across the whole country in early 2020 also aroused widespread public concern about health; epidemics in different regions one after another in China have occupied the public view; information about the prevention and control of infectious diseases or the epidemic situation filled the website and public platforms, and diet habits and travel patterns changed, and therefore, the salt-related knowledge and behaviors status of residents may also change. WeChat is a popular social application in China with over 1 million monthly active users; about 63 million users over 55-years-old actively used WeChat on a monthly basis in 2018 from Tencent's report. Lots of health-related information have been published on the WeChat platform, many of which are unverified or inaccurate due to the uneven quality of the publishing organizations. However, official public health WeChat accounts such as the CHLA public platform has been continuously publishing and pushing the scientific authoritative health knowledge through the platform, which can also realize the two-way interaction between the publishing organization and 
the recipient and can reach more people faster than offline activities. The WeChat public platform has been widely used by health education and public health institutions [31,32]. Then, these institutions could conduct related surveys through the platform to evaluate the publicity effectiveness of their activities among their target WeChat users and to further improve the quality of their work. Besides, an online survey in WeChat can save time and cost for the organizers and participants; the respondents can participate at any time of the day and it has little interference with the respondents' daily life. To explore the status of salt-related knowledge and behaviors in 2019 and the changes 1 year later, while taking into account the active role of the WeChat platform in promoting health education and its advantages in an online investigation, we conducted a 10 day salt-related survey on an official WeChat public platform of CHLA in 2019 and 2020, separately. Salt-related knowledge, willingness and behaviors were analyzed. Scores of salt-related knowledge, salt reduction behavior and high-salt intake behavior in different groups between 2019 and 2020 were calculated and compared.

\section{Materials and Methods}

\subsection{Data Source}

The WeChat public platform of China Healthy Lifestyle for All Campaign (ID: qmjkshfsxd) was built in 2014; articles about healthy lifestyles including graphics, audio and video were published on this platform from time to time. The followers of this WeChat public platform had increased significantly year by year, and it was followed by 63,793 WeChat users on December 31 of 2018. A ten day salt-related survey was conducted on this WeChat public platform in 2019 (24 September-3 October) and 2020 (11-20 September). The online survey was approved by Chinese Center for Disease Control and Prevention Institutional Review Board (No.202108). The online survey was only published one time each year on this WeChat public platform, the link address of this survey was posted and pushed to all the followers of the platform and then forwarded to the WeChat Moments. All WeChat users can enter the survey platform through the link address to fill out the questionnaire online independently. After the survey completed, the data of participants were recorded in the form of online submission on WeChat. The survey record could not be submitted if the respondent failed to answer all questions. After submitting, the correct answers were not provided to the participant to avoid contamination of survey results between different participants. Additionally, we provided a "salt-score" (total score $=100$ points) to each participant based on their record, and they could share this score with their friends from WeChat Moments, which was aimed at improving the sense of participation of respondents and to attract more WeChat users to participate in this survey.

\subsection{WeChat-Based Survey}

General information of each participant was investigated at first, including gender, age, education level, region and self-reported health status. Then, the participant was invited to complete a salt-related knowledge, willingness and behavior questionnaire. This questionnaire was designed based on the 10 core messages of salt reduction publicity week published by National Health Commission of the People's Republic of China at 20 August 2019 [28], and the draft of the questionnaire was revised by two rounds of expert seminars. Before the questionnaire was officially posted, a small-scale population pre-survey was carried out, and the questionnaire was improved based on the feedback results to ensure that the questions were clear and understandable. Main summary of this survey can be found in Supplementary Table S1. The time taken to complete the questionnaire was automatically recorded to identify the unreasonable records. The average answering time of the participants in the pre-survey was $1.6 \mathrm{~min}$, with a range of $1.1-2.8 \mathrm{~min}$.

\subsection{Salt-Related Knowledge and Behavior Scores}

Four questions were applied to assess salt-knowledge status (total scores $=13$ ): knowledge about foods that contain salt, condiments that contain salt and should be used less, 
maximum daily salt intake of healthy adults and diseases that related to excessive salt intake. For question "foods that contain salt", five foods contained salt, but no salty taste was chosen, including fine dried noodles, bread, biscuit, cheese and ice cream, and each food was scored 1 point. Soy sauce, oyster sauce, bean paste and monosodium glutamate (MSG) were chosen for the question, "Condiments that contain salt and should be used less"; each condiment scored 1 point. For the question, "Maximum daily salt intake of healthy adults", six options were provided, including $2 \mathrm{~g}$, $4 \mathrm{~g}, 5 \mathrm{~g}, 6 \mathrm{~g}$, $8 \mathrm{~g}$ and do not know, but only the response of $5 \mathrm{~g}$ or $6 \mathrm{~g}$ can score 1 point. Three diseases, including hypertension, heart disease and stroke were presented for "Diseases that related to excessive salt intake"; each disease scored 1 point.

Six behaviors related to salt reduction (total scores $=6$ ) were considered in this questionnaire: using salt measuring spoons, asking restaurants to use less salt, reading the sodium content on the nutrition facts table, choosing foods with low sodium content, regularly using low-sodium salt, using chili, garlic, vinegar, pepper, etc. to enhance the flavor of food and gradually reducing the amount of salt used in cooking. Participants can respond "Have this behavior" or "Did not have this behavior" for each behavior, and only people who had the behavior can score 1 point.

High salt intake behavior (total scores $=9$ ): frequency of using high-salt condiments such as oyster sauce, bean paste, MSG, etc., frequency of eating processed foods and canned foods, frequency of eating pickled mustard tubers, salted vegetables and sauce foods. Each behavior was classified into four levels: "Regularly", "Occasionally", "Rarely" and "Never". The response of "Regularly" scored 3 points, "Occasionally" scored 2 points, "Rarely" scored 1 point and "Never" scored 0. More information about the calculation method of salt-related knowledge and behavior scores is presented in Table 1.

Table 1. The calculation method of salt-related knowledge and behavior scores.

\begin{tabular}{|c|c|c|c|}
\hline & Questions & Score & Setting \\
\hline \multirow{4}{*}{$\begin{array}{l}\text { Salt-related knowledge score } \\
\quad(\text { total scores }=13)\end{array}$} & Foods that contain salt & 5 & $\begin{array}{l}\text { Fine dried noodles }=1 \text {, Bread }=1 \text {, Biscuit }=1 \text {, } \\
\qquad \text { Cheese }=1 \text {, Ice cream }=1\end{array}$ \\
\hline & $\begin{array}{l}\text { Condiments that contain salt } \\
\text { and should be used less }\end{array}$ & 4 & $\begin{array}{c}\text { Soy sauce }=1, \text { Oyster sauce }=1 \\
\text { Bean paste }=1, \text { MSG }=1\end{array}$ \\
\hline & $\begin{array}{l}\text { Maximum daily salt intake of } \\
\text { healthy adults }\end{array}$ & 1 & $5 \mathrm{~g}$ or $6 \mathrm{~g}=1$ \\
\hline & $\begin{array}{l}\text { Diseases that related to } \\
\text { excessive salt intake }\end{array}$ & 3 & $\begin{array}{c}\text { Hypertension }=1, \text { Heart disease }=1, \\
\text { Stroke }=1\end{array}$ \\
\hline \multirow{6}{*}{$\begin{array}{l}\text { Salt-reduction behavior score } \\
\quad(\text { total scores }=6)\end{array}$} & Use salt measuring spoons & 1 & Have this behavior $=1$ \\
\hline & Ask restaurants to use less salt & 1 & Have this behavior $=1$ \\
\hline & $\begin{array}{l}\text { Read the sodium content on } \\
\text { the nutrition facts table }\end{array}$ & 1 & Have this behavior $=1$ \\
\hline & $\begin{array}{l}\text { Choose foods with low } \\
\text { sodium content }\end{array}$ & 1 & Have this behavior $=1$ \\
\hline & $\begin{array}{l}\text { Regularly use low-sodium salt } \\
\text { Use chili, garlic, vinegar, } \\
\text { pepper, etc. to enhance the }\end{array}$ & 1 & Have this behavior $=1$ \\
\hline & $\begin{array}{l}\text { flavor of food and gradually } \\
\text { reduce the amount of salt } \\
\text { used in cooking }\end{array}$ & 1 & Have this behavior $=1$ \\
\hline \multirow{3}{*}{$\begin{array}{l}\text { High salt intake behavior } \\
\text { score }(\text { total scores }=9)\end{array}$} & $\begin{array}{l}\text { Frequency of using high-salt } \\
\text { condiments such as oyster } \\
\text { sauce, bean paste, MSG, etc. }\end{array}$ & 3 & $\begin{array}{c}\text { Regularly }=3, \text { Occasionally }=2, \text { Rarely }=1, \\
\text { Never }=0\end{array}$ \\
\hline & $\begin{array}{l}\text { Frequency of eating processed } \\
\text { foods and canned foods }\end{array}$ & 3 & $\begin{array}{c}\text { Regularly }=3, \text { Occasionally }=2, \text { Rarely }=1, \\
\text { Never }=0\end{array}$ \\
\hline & $\begin{array}{l}\text { Frequency of eating pickled } \\
\text { mustard tubers, salted } \\
\text { vegetables and sauce foods }\end{array}$ & 3 & $\begin{array}{c}\text { Regularly }=3, \text { Occasionally }=2, \text { Rarely }=1, \\
\text { Never }=0\end{array}$ \\
\hline
\end{tabular}




\subsection{Statistical Analysis}

Descriptive statistics including frequency and percentage, median and interquartile range (IQR) were conducted for general variables, salt-related knowledge and behaviors. The comparison of general information, salt-related knowledge and behaviors status in 2019 and 2020 was conducted using the chi-square test. Since salt-related knowledge and behavior scores were not of normal distribution as tested by the Kolmogorov-Smirnov test, the Wilcoxon rank sum test was used for comparing salt-related knowledge and behavior scores between 2019 and 2020. Wilcoxon rank-sum test and Kruskal-Wallis test were used for comparing the salt-related knowledge and behavior scores between subgroups. The correlation of salt-related knowledge and behavior scores was examined by Spearman correlation analysis. All statistical analyses were performed in the SPSS 22.0 software (SPSS Inc., Chicago, IL, USA), and the significance level was 0.05 .

\section{Results}

\subsection{General Information}

During the survey periods, a total of 2362 records in 2019 and 14947 records were collected. After excluding the duplicate records from the same individuals or the answering time lower than 1 min or not from the mainland of China, 2109 participants' data in 2019 and 12732 participants' data in 2020 were left for further analysis. The general information of these participants is presented in Table 2.

Table 2. General information.

\begin{tabular}{|c|c|c|c|c|c|c|}
\hline \multirow[t]{2}{*}{ Variables } & \multicolumn{2}{|c|}{ Year $2019(N=2109)$} & \multicolumn{2}{|c|}{ Year $2020(N=12,732)$} & \multirow{2}{*}{$x^{2}$} & \multirow{2}{*}{$p$-Value } \\
\hline & $N$ & $\%$ & $N$ & $\%$ & & \\
\hline Gender & & & & & 0.374 & 0.541 \\
\hline Male & 629 & 29.8 & 3714 & 29.2 & & \\
\hline Female & 1480 & 70.2 & 9018 & 70.8 & & \\
\hline Age & & & & & 17.036 & $<0.001$ \\
\hline$\leq 45$ & 1377 & 65.3 & 7711 & 60.6 & & \\
\hline$>45$ & 732 & 34.7 & 5021 & 39.4 & & \\
\hline Education level & & & & & 251.467 & $<0.001$ \\
\hline Middle school and below & 170 & 8.1 & 2031 & 16.0 & & \\
\hline High school & 556 & 26.4 & 4214 & 33.1 & & \\
\hline College & 1177 & 55.8 & 5968 & 46.9 & & \\
\hline Postgraduate & 206 & 9.8 & 519 & 4.1 & & \\
\hline Region & & & & & 477.862 & $<0.001$ \\
\hline East & 764 & 36.2 & 5393 & 42.4 & & \\
\hline Middle & 852 & 40.4 & 2482 & 19.5 & & \\
\hline West & 493 & 23.4 & 4857 & 38.1 & & \\
\hline Answering time & & & & & 61.155 & $<0.001$ \\
\hline$\geq 1-2 \min$ & 769 & 36.5 & 3714 & 29.2 & & \\
\hline$\geq 2-5 \mathrm{~min}$ & 1263 & 59.9 & 8195 & 64.4 & & \\
\hline$\geq 5 \mathrm{~min}$ & 77 & 3.7 & 823 & 6.5 & & \\
\hline \multicolumn{7}{|l|}{ Self-reported health status } \\
\hline Hypertension & 237 & 11.2 & 1677 & 13.2 & 6.024 & 0.014 \\
\hline Basic health & 1826 & 86.6 & 10790 & 84.7 & 4.776 & 0.029 \\
\hline
\end{tabular}


Table 2. Cont.

\begin{tabular}{|c|c|c|c|c|c|c|}
\hline \multirow[t]{2}{*}{ Variables } & \multicolumn{2}{|c|}{ Year $2019(N=2109)$} & \multicolumn{2}{|c|}{ Year $2020(N=12,732)$} & \multirow{2}{*}{$x^{2}$} & \multirow{2}{*}{$p$-Value } \\
\hline & $N$ & $\%$ & $N$ & $\%$ & & \\
\hline Salt-related taste & & & & & 2.645 & 0.266 \\
\hline Salty & 494 & 23.4 & 2781 & 21.8 & & \\
\hline Moderate & 1113 & 52.8 & 6842 & 53.7 & & \\
\hline Bland & 502 & 23.8 & 3109 & 24.4 & & \\
\hline Willingness for salt reduction & & & & & 9.163 & 0.027 \\
\hline Yes & 1861 & 88.2 & 11487 & 90.2 & & \\
\hline No & 130 & 6.2 & 694 & 5.5 & & \\
\hline Do not care & 102 & 4.8 & 485 & 3.8 & & \\
\hline Do not know & 16 & 0.8 & 66 & 0.5 & & \\
\hline
\end{tabular}

Most participants answered the questionnaire within 1 to $5 \mathrm{~min}$. Among those participants in $2019,29.8 \%(n=629)$ were male, $34.7 \%(n=732)$ were over 45 -year-old, $8.1 \%$ $(n=170)$ had an education level of middle school and below, $40.4 \%(n=852)$ came from the middle region and $11.2 \%(n=237)$ were self-reported hypertension patients. Among those participants in 2020, 29.2\% $(n=3714)$ were male, 39.4\% ( $n=5021)$ were over 45 years old, $16.0 \%(n=2031)$ had an education level of middle school and below, $19.5 \%(n=2482)$ came from the middle region and $13.2 \%(n=1677)$ were self-reported hypertension patients. Variables including age, education level, region, answering time and self-reported health status were significantly different between 2019 and 2020 ( $p$-value $<0.05$ ).

In $2019,23.4 \%, 52.8 \%$ and $23.8 \%$ of participants reported that they had salty, moderate and bland taste, compared to $21.8 \%, 53.7 \%$ and $24.4 \%$ in 2020 , respectively. $88.2 \%$ of participants in 2019 had a willingness to reduce the amount of cooking salt in their households, significantly lower than $90.2 \%$ in 2020 ( $p$-value $<0.05$ ).

\subsection{Salt-Related Knowledge}

Results of salt-related knowledge status of participants from 2019 and 2020 are presented in Figure 1. The percentage of knowing all five foods contained salt in 2019 was $24.5 \%$, significantly higher than $17.7 \%$ in 2020 ( $p$-value < 0.05). In 2019 and 2020, over $80 \%$ of the participants knew fine dried noodles contain salt, but less than $30 \%$ knew ice cream contain salt. The percentage of those knowing fine dried noodles, bread, biscuit, cheese and ice cream contain salt in 2019 were significantly higher than those in 2020 (all $p$-value < 0.05), respectively. A number of $63.1 \%$ in 2019 and $61.5 \%$ in 2020 of participants believed all four condiments contain salt and should be used less, with no significant difference ( $p$-value $=0.15$ ). Over $78 \%$ of participants chose $5 \mathrm{~g}$ or $6 \mathrm{~g}$ for the maximum daily salt intake of healthy adults in both years. The proportion of choosing $5 \mathrm{~g}$ as the maximum daily salt intake of healthy adults decreased from $42.3 \%$ in 2019 to $35.4 \%$ in $2020,40.6 \%$ and $43.1 \%$ for choosing $6 \mathrm{~g}$. About $98 \%$ of participants knew that excessive salt intake would increase the risk of hypertension in 2019 and 2020. However, only 77.4\% in 2019 and 74.0\% in 2020 of participants knew that strokes related to excessive salt intake, with a significant difference $(p$-value $<0.05)$.

\subsection{Salt-Related Behaviors}

Figure 2 provides the results of salt reduction behaviors status between 2019 and 2020. The percentages of participants who used salt measuring spoons, asked restaurants to use less salt, read the sodium content on the nutrition facts table, chose foods with low sodium content and regularly used low-sodium salt, were $36.1 \%, 45.0 \%, 44.1 \%, 40.3 \%$ and $35.8 \%$ in 2019 , and the percentage increased significantly to $46.4 \%, 49.2 \%, 50.8 \%, 47.1 \%$ and $43.4 \%$ in 2020 (all $p$-value $<0.05$ ). A number of $81.7 \%$ of participants used chili, garlic, vinegar, pepper, etc. to enhance the flavor of food and gradually reduced the amount of salt used in cooking in 2019, slightly increased to $82.7 \%$ in 2020 ( $p$-value $=0.057)$. 
a

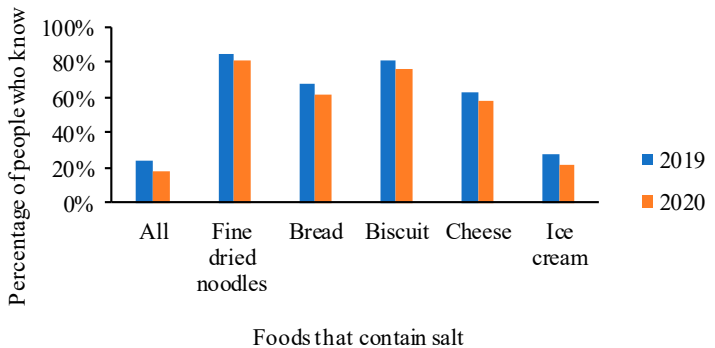

c

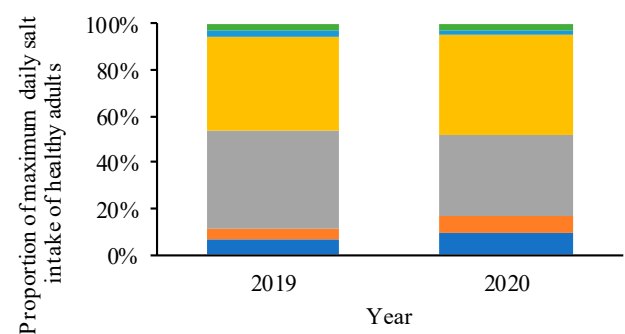

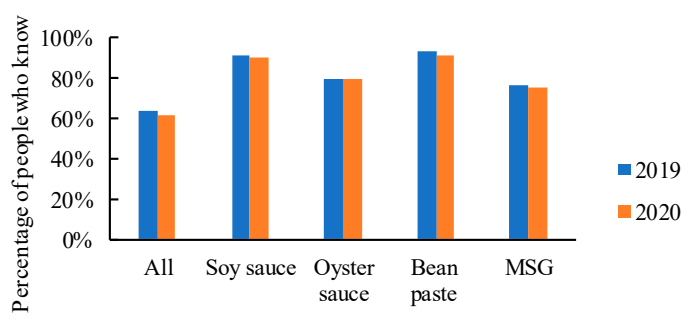

Condiments that contain salt and should be used less

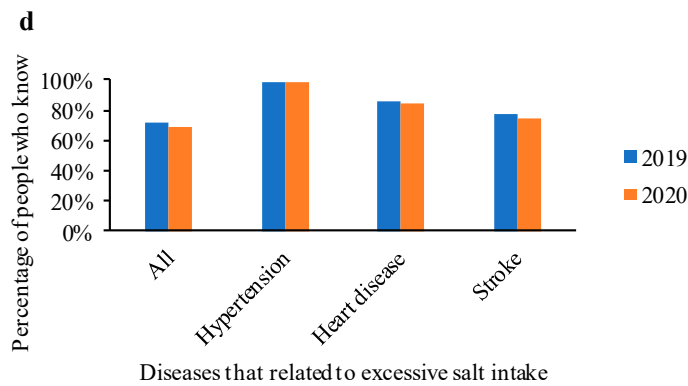

Figure 1. Comparison of salt-related knowledge status between 2019 and 2020. (a) Foods that contain salt; (b) condiments that contain salt and should be used less; (c) maximum daily salt intake of healthy adults; (d) diseases that related to excessive salt intake.

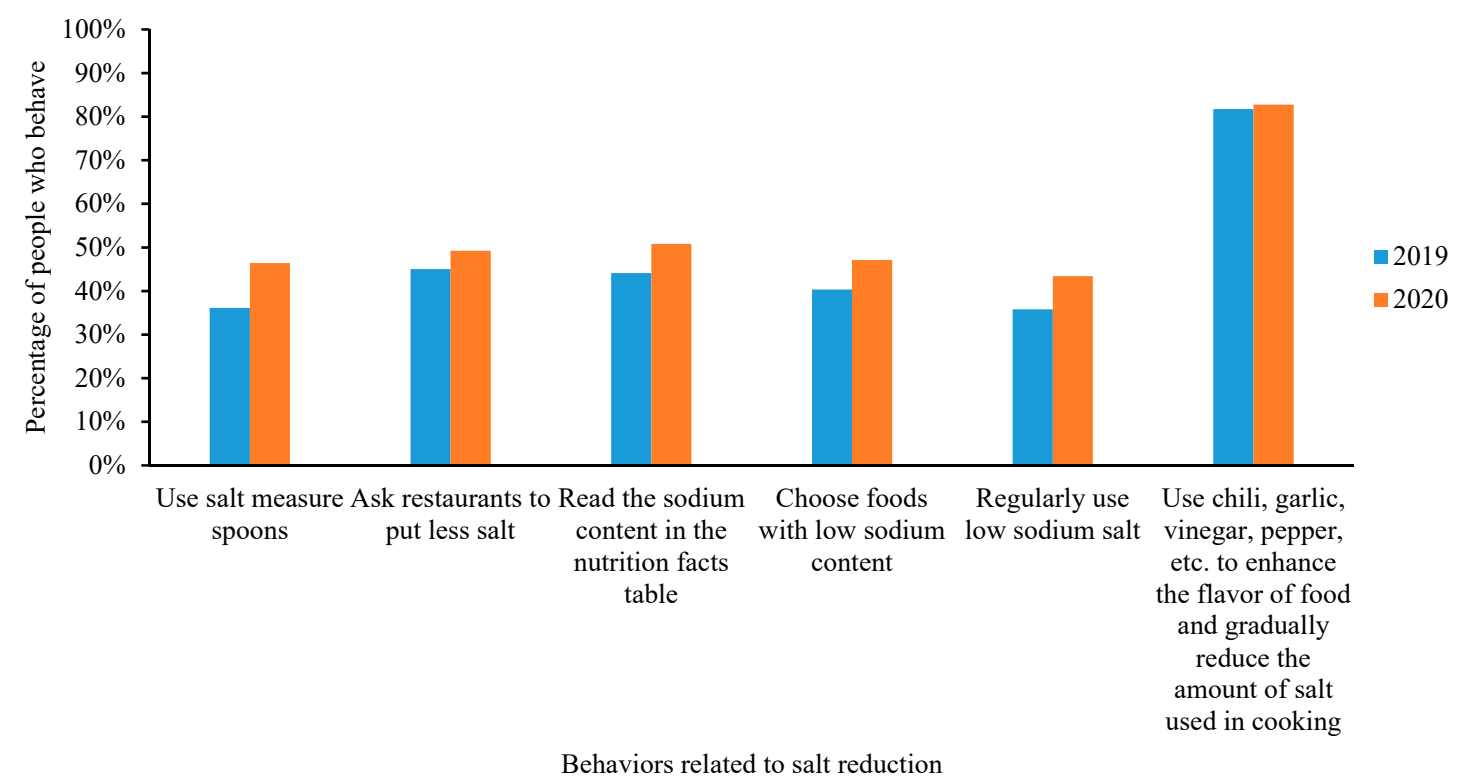

Figure 2. Comparison of behaviors status related to salt reduction between 2019 and 2020.

Results of behaviors status related to high salt intake between 2019 and 2020 are shown in Figure 3. 


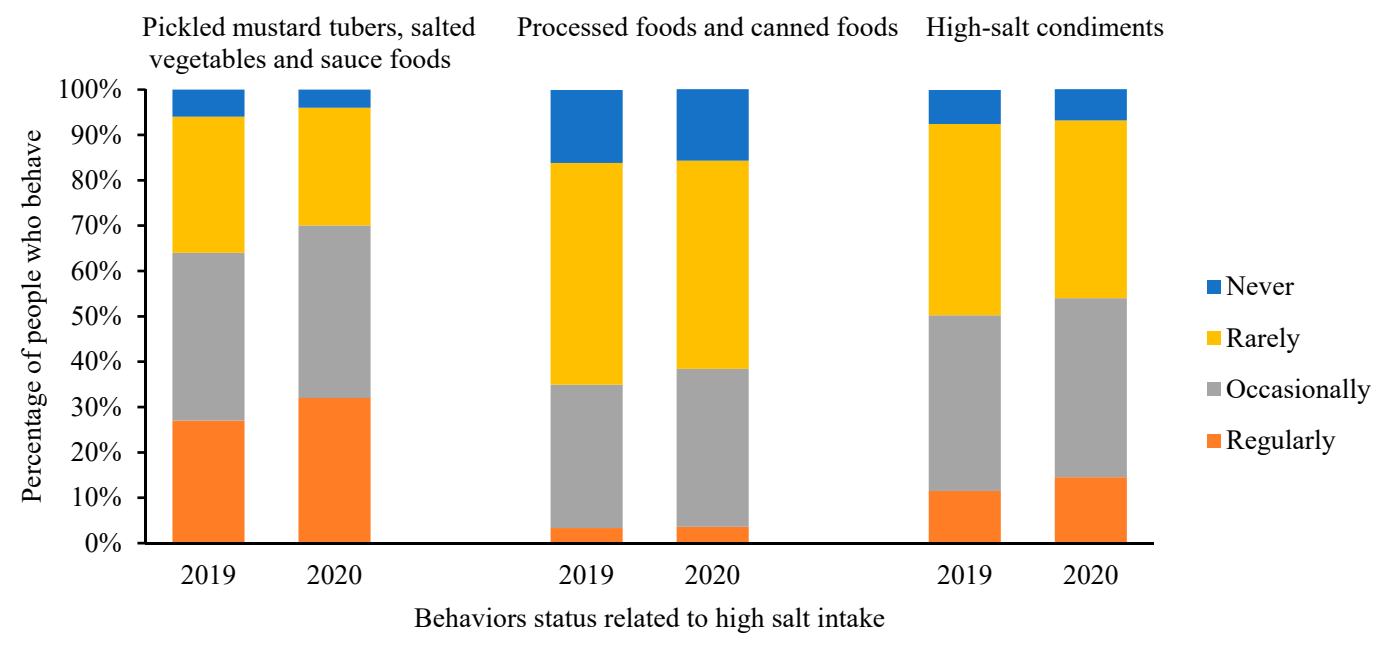

Figure 3. Comparison of behaviors status related to high salt intake between 2019 and 2020.

The percentage of regularly eating pickled mustard tubers, salted vegetables and sauce foods increased from $27.3 \%$ in 2019 to $31.4 \%$ in 2020, and the order of different frequencies changed from occasionally $>$ rarely $>$ regularly $>$ never in 2019 to occasionally $>$ regularly $>$ rarely > never in 2020 . Compared to $11.5 \%$ in 2019 , the percentage of regularly using high-salt condiments such as oyster sauce, bean paste and MSG increased by 3\% in 2020.

\subsection{Salt-Related Knowledge and Behavior Scores}

Salt-related knowledge score, salt reduction behavior score and high-salt intake behavior score were calculated separately, and the results were summarized in Table 3 . The median of salt-related knowledge scores, salt reduction behavior scores and high-salt intake behavior scores were 11, 2 and 5 points in 2019 and 10, 3 and 5 points in 2020, respectively. Compared to 2019, the salt-related knowledge score was relatively lower, while the salt reduction behavior score and high-salt intake behavior score were relatively higher in 2020, and similar differences between two years still existed in age, hypertension and salt related-taste groups (all $p$-value $<0.05$ ).

Table 3. Distribution of salt-related knowledge and behavior scores in 2019 and 2020 (Median (IQR)).

\begin{tabular}{|c|c|c|c|c|c|c|c|c|c|c|c|c|}
\hline \multirow{2}{*}{ Variables } & \multicolumn{4}{|c|}{ Salt-Related Knowledge Score } & \multicolumn{4}{|c|}{ Salt Reduction Behavior Score } & \multicolumn{4}{|c|}{ High-Salt Intake Behavior Score } \\
\hline & 2019 & 2020 & $\mathbf{Z}$ & $p$-Year & 2019 & 2020 & $\mathbf{Z}$ & $p$-Year & 2019 & 2020 & $\mathbf{Z}$ & $p$-Year \\
\hline Total & 11(3) & $10(4)$ & 6.908 & $<0.001$ & 2(3) & $3(4)$ & -8.132 & $<0.001$ & $5(3)$ & $5(2)$ & -4.947 & $<0.001$ \\
\hline \multicolumn{13}{|l|}{ Gender } \\
\hline Male & 10(4) & $10(3)$ & 4.391 & $<0.001$ & 2(3) & $3(4)$ & -5.784 & $<0.001$ & $5(3)$ & $5(2)$ & -1.814 & 0.070 \\
\hline Female & $11(3)$ & $10(4)$ & 5.431 & $<0.001$ & $3(3)$ & $3(4)$ & -5.917 & $<0.001$ & $5(3)$ & $5(2)$ & -4.761 & $<0.001$ \\
\hline$p$-group & 0.001 & $<0.001$ & & & 0.173 & 0.137 & & & 0.013 & 0.001 & & \\
\hline \multicolumn{13}{|l|}{ Age } \\
\hline$\leq 45$ & 11(3) & $10(4)$ & 6.157 & $<0.001$ & 2(3) & $3(4)$ & -5.857 & $<0.001$ & $5(3)$ & $5(2)$ & -4.029 & $<0.001$ \\
\hline$>45$ & $10(4)$ & $10(4)$ & 2.730 & 0.006 & $3(3)$ & $4(3)$ & -5.035 & $<0.001$ & $4(3)$ & $5(3)$ & -3.458 & $<0.001$ \\
\hline P-group & $<0.001$ & $<0.001$ & & & $<0.001$ & $<0.001$ & & & $<0.001$ & $<0.001$ & & \\
\hline \multicolumn{13}{|l|}{$\begin{array}{l}\text { Education } \\
\text { level }\end{array}$} \\
\hline $\begin{array}{l}\text { Middle school } \\
\text { and below }\end{array}$ & $8(4)$ & $9(5)$ & -2.003 & 0.045 & 2(3) & $3(3)$ & -5.746 & $<0.001$ & $4(3)$ & $5(3)$ & -2.779 & 0.005 \\
\hline High school & $9(4)$ & $10(3)$ & -1.447 & 0.148 & $3(4)$ & 3(3) & -5.445 & $<0.001$ & $5(3)$ & $5(3)$ & -2.467 & 0.014 \\
\hline College & $11(3)$ & $11(3)$ & 4.123 & $<0.001$ & $2(4)$ & $3(4)$ & -3.621 & $<0.001$ & $5(3)$ & $5(2)$ & -4.112 & $<0.001$ \\
\hline Postgraduate & $12(2)$ & $11(3)$ & 2.906 & 0.004 & $3(3)$ & $3(3)$ & 0.285 & 0.776 & $5(3)$ & $5(2)$ & -1.247 & 0.212 \\
\hline p-group & $<0.001$ & $<0.001$ & & & 0.028 & $<0.001$ & & & 0.072 & $<0.001$ & & \\
\hline
\end{tabular}


Table 3. Cont.

\begin{tabular}{|c|c|c|c|c|c|c|c|c|c|c|c|c|}
\hline \multirow{2}{*}{ Variables } & \multicolumn{4}{|c|}{ Salt-Related Knowledge Score } & \multicolumn{4}{|c|}{ Salt Reduction Behavior Score } & \multicolumn{4}{|c|}{ High-Salt Intake Behavior Score } \\
\hline & 2019 & 2020 & $\mathbf{Z}$ & $p$-Year & 2019 & 2020 & $\mathbf{Z}$ & $p$-Year & 2019 & 2020 & $\mathbf{Z}$ & $p$-Year \\
\hline \multicolumn{13}{|l|}{ Region } \\
\hline East & 11(3) & $10(4)$ & 6.890 & $<0.001$ & $3(4)$ & $4(3)$ & -6.342 & $<0.001$ & $5(3)$ & $5(2)$ & -2.891 & 0.004 \\
\hline Middle & $10(4)$ & $10(4)$ & -1.379 & 0.168 & $2(3)$ & $3(4)$ & -3.195 & 0.001 & $5(3)$ & $5(3)$ & -1.820 & 0.069 \\
\hline West & $11(4)$ & $10(3)$ & 5.263 & $<0.001$ & $2(3)$ & $3(4)$ & -4.055 & $<0.001$ & $5(3)$ & $5(2)$ & -2.729 & 0.006 \\
\hline$p$-group & $<0.001$ & $<0.001$ & & & $<0.001$ & $<0.001$ & & & 0.535 & $<0.001$ & & \\
\hline \multicolumn{13}{|l|}{$\begin{array}{l}\text { Answering } \\
\text { time }\end{array}$} \\
\hline$\geq 1-2 \min$ & $11(4)$ & 11(3) & 5.383 & $<0.001$ & 2(3) & $3(4)$ & -2.192 & 0.0284 & $5(3)$ & $5(2)$ & -3.939 & $<0.001$ \\
\hline$\geq 2-5$ min & 10(4) & $10(4)$ & 2.681 & 0.007 & $3(4)$ & $3(3)$ & -7.134 & $<0.001$ & 5(3) & $5(3)$ & -3.853 & $<0.001$ \\
\hline$\geq 5 \min$ & $9(4)$ & $9(4)$ & 2.012 & 0.044 & $2(4)$ & $4(3)$ & -2.864 & 0.004 & $5(3)$ & $5(3)$ & -0.563 & 0.574 \\
\hline $\bar{p}$-group & $<0.001$ & $<0.001$ & & & 0.736 & $<0.001$ & & & 0.051 & $<0.001$ & & \\
\hline \multicolumn{13}{|c|}{ Hypertension } \\
\hline Yes & $10(4)$ & $10(4)$ & 2.007 & 0.045 & 2(3) & $3(3)$ & -4.445 & $<0.001$ & $5(2)$ & $5(3)$ & -2.049 & 0.041 \\
\hline No & 11(3) & $10(4)$ & 6.519 & $<0.001$ & $3(3)$ & $3(4)$ & -6.989 & $<0.001$ & $5(3)$ & $5(2)$ & -4.398 & $<0.001$ \\
\hline$p$-group & 0.019 & $<0.001$ & & & 0.468 & 0.002 & & & 0.011 & $<0.001$ & & \\
\hline \multicolumn{13}{|l|}{$\begin{array}{l}\text { Salt-related } \\
\text { taste }\end{array}$} \\
\hline Salty & $11(4)$ & $10(4)$ & 3.143 & 0.002 & 2(2) & 2(3) & -3.452 & $<0.001$ & $6(2)$ & 6(2) & -2.216 & 0.027 \\
\hline Moderate & 11(3) & $10(4)$ & 4.120 & $<0.001$ & 2(3) & $3(3)$ & -6.826 & $<0.001$ & 5(3) & $5(2)$ & -4.160 & $<0.001$ \\
\hline Bland & $11(3)$ & $10(4)$ & 5.048 & $<0.001$ & $4(3)$ & $4(4)$ & -3.520 & $<0.001$ & $4(2)$ & $4(2)$ & -3.530 & $<0.001$ \\
\hline$p$-group & 0.011 & $<0.001$ & & & $<0.001$ & $<0.001$ & & & $<0.001$ & $<0.001$ & & \\
\hline \multicolumn{13}{|l|}{$\begin{array}{l}\text { Willingness } \\
\text { for salt } \\
\text { reduction }\end{array}$} \\
\hline Yes & 11(3) & $10(4)$ & 7.009 & $<0.001$ & $3(4)$ & $3(3)$ & -7.276 & $<0.001$ & $5(3)$ & $5(2)$ & -5.208 & $<0.001$ \\
\hline No & $9(4)$ & $9(5)$ & 1.929 & 0.054 & $1(1)$ & $1(1)$ & -1.422 & 0.155 & $5(3)$ & $6(3)$ & -0.897 & 0.370 \\
\hline$p$-group & $<0.001$ & $<0.001$ & & & $<0.001$ & $<0.001$ & & & $<0.001$ & $<0.001$ & & \\
\hline
\end{tabular}

Note: $p$-year is the $p$-value of Wilcoxon rank-sum test for comparing salt-related knowledge and behavior scores between 2019 and 2020. Note: $p$-group is the $p$-value of the comparison of salt-related knowledge and behavior scores between different groups. Wilcoxon rank-sum test was used for gender, age and hypertension. Kruskal-Wallis test was used for education level, region, answering time, salt-related taste and willingness for salt reduction.

The salt-related knowledge and behavior scores among different groups were also compared. In both 2019 and 2020, salt-related knowledge scores of females were higher than those of males, while their high-salt intake behavior scores were lower than males; salt-related knowledge and high-salt intake behavior scores in the 45-years-old-and-below group were higher, but the salt reduction behavior score was relatively lower than the over-45-years-old group; higher education level came with higher scores of salt-related knowledge and salt reduction behaviors; for participants with salty taste or without a willingness for salt reduction, salt-related knowledge and salt reduction behaviors scores were low, but the high-salt intake behavior scores were high.

\section{Discussion}

This study found that the percentage of WeChat users who had the willingness of reducing the amount of cooking salt in their households was quite high between 2019 and 2020 in China, but the awareness level of salt-related knowledge varied greatly, similar to the result of a survey of 2444 Chinese consumers in 2017 [33]. Over $60 \%$ of participants knew all four provided condiments contain salt and should be used less or three types of diseases related to excessive salt intake, but lower than $25 \%$ of participants knew all the five foods listed contain salt in this study. There is hidden salt in foods like fine dried noodles, bread, biscuit, cheese and ice cream. Over $80 \%$ of participants knew fine dried noodles contains salt in 2019 and 2020, higher than $40.8 \%$ of knowing dragon beard noodles (a kind of fine dried noodles) contains salt in 2017 [33], but lower than $30 \%$ knew ice cream contains salt, which may be due to the sweetness and low sodium content of ice cream [34]. Unlike western countries, the main sources of sodium in China residents are cooking salt, 
soy sauce and other condiments; most come from home cooking $[14,35]$. Soy sauce, oyster sauce, bean paste and MSG are four condiments commonly used in daily life with high sodium content [34], but only less than $64 \%$ of participants believed all four condiments contain salt and should be used less. The relationship between salt intake and blood pressure has been confirmed and is widely publicized [7,28,29]; 98\% of participants in this study knew that excessive salt intake would increase the risk of hypertension in 2019 and 2020, the percentages of participants who knew that excessive salt intake would increase the risk of cardiovascular diseases such as high blood pressure, heart diseases and stroke were all higher than those of Chinese consumers in 2017 [33], older rural Chinese adults in 2010 [36] and even Chinese hypertensive patients [37]. Obviously, the harmful effects of high salt intake have been widely accepted by Chinese residents.

The publicity and advocacy of the recommended maximum daily salt intake are helpful for carrying out public health interventions and salt-reduction behaviors [12,38,39]. The Dietary Guidelines of Chinese Residents 2016 and 2018 Chinese guidelines for the management of hypertension all recommended that the maximum daily salt intake of healthy adults should not exceed $6 \mathrm{~g}[13,40]$. A number of $41 \%$ in 2019 and $43 \%$ in 2020 of participant knew $6 \mathrm{~g}$ was the maximum daily salt intake of healthy adults, close to $45.8 \%$ of Chinese hypertensive patients [37], but much higher than $6.1 \%$ in 2015 [27] and 5.0\% in older rural Chinese adults in 2010 [36], credited to the advocacy and education efforts of these years. World Health Organization and the Healthy China Initiative (2019-2030) recommended that the daily salt intake of adults should not exceed $5 \mathrm{~g}$ [12,41], and publicity and advocacy of CHLA Campaign and Salt Reduction Publicity Week adopted this recommendation in 2019 [28]. In this study, over $78 \%$ of participants chose $5 \mathrm{~g}$ or $6 \mathrm{~g}$ for the maximum daily salt intake of healthy adults in both years, higher than $35 \%$ in Chinese consumers in 2017 [33]. Additionally, the percentage of participant identified $5 \mathrm{~g} /$ day in this study was higher than those in Los Angeles county residents [39] and Australia Victorian [22], but the percentage decreased from 2019 to 2020; a similar downward trend can be found in the awareness of foods that contain salt, oyster sauce should be eaten less, stroke related to excessive salt intake and the salt-related knowledge score. One possible explanation is that most publicity and education activities of salt reduction were conducted in 2019 [18,28,29], and the sudden appearance of the COVID-19 pandemic attracted public attention in 2020, leading to a decline in salt-related knowledge.

Behaviors such as using a quantitative salt spoon and reading the sodium content of food products can help people understand the amount of salt intake, then take salt constriction behaviors [19,42]. Asking restaurants to use less salt, choosing foods with low sodium content, regularly using low-sodium salt and using chili, garlic, vinegar, pepper other than salt can directly reduce the amount of salt used in cooking. Additionally, these above measures were often used or suggested in salt-reduction intervention activities $[15,19,43]$. The behavior rates of salt reduction of Chinese adult residents was $42.2 \%$ in 2010 and $37.3 \%$ in 2015 [27,44], and the percentage of the six chosen salt reduction behaviors were all higher than $35 \%$ in this study; over $81 \%$ of participants used chili, garlic, vinegar or pepper to enhance the flavor of food and gradually reduced the amount of salt used in cooking, and the percentage using more/other spices than salt to add flavor to food was only $42 \%$ in US adults [23], almost the half of this study, which may be due to the difference of eating habits between two countries. Additionally, the percentage of action to reduce sodium intakes such as choosing low-sodium foods or snacks, checking nutrition labels for sodium content or buying foods labeled low-sodium ranged from $34 \%$ to $36 \%$ in US adults [23], close to the result of this study. High salt intake behaviors, including regularly eating pickled mustard tubers, salted vegetables and sauce foods and using high-salt condiments, increased from 2019 to 2020, as well as the high-salt intake behaviors score, which might be related to the increase in the proportion of eating at home in 2020. For the prevention and control of the COVID-19 epidemic, more Chinese people were advised to reduce eating out and instead cook at home. Related studies reported that significant increases were observed in the frequency of consumption of preserved vegetables [45], 38.2\% of Chinese 
residents increased their snack intake during the COVID-19 lockdown [46] and 61.6\% of participants decreased eating in restaurants, while $64.8 \%$ of participants reported increased cooking at home post-lockdown [47], which may lead to an increase in the frequency of eating high-salt condiments and foods.

Females and better-educated people were more likely to have higher levels of saltrelated knowledge, and they were more interested in and more active in salt reduction [21,25,33,48]. In this study, it was also found that in both 2019 and 2020, higher education levels came with higher scores of salt-related knowledge and salt reduction behaviors; females had higher salt-related knowledge scores and relatively lower high-salt intake behavior scores, but the salt reduction behavior score did not differ by gender. In most families of China, female are responsible for cooking, and they care about the healthy diet of family members, which may lead to more attention to salt-related knowledge. It was reported that better-educated people, females and young people were more knowledgeable about salt-reduction tips [33]; a similar result was found in this study, and the salt-related knowledge of the 45-years-old-and-below group was higher than those in over-45-years-old group. It should be noted that low salt-related knowledge, salt reduction score and highsalt intake behavior score were found in the hypertension patients group in this study. A previous study also found that hypertensive patients with knowledge of the recommended salt intake had a higher control rate than those without [37]. Therefore, it is necessary to carry out targeted publicity and education on salt reduction knowledge for male and hypertensive patients so as to encourage them to reduce their high-salt diet behaviors.

This study was based on the WeChat platform for all WeChat users. The subjects voluntarily participated in the online survey and could exit freely, and the results of the survey were more in line with the real situation of the participants. However, there are also several limitations in our study. First, the questionnaire was pushed to all WeChat users based on the CHLA public platform; self-reported gender, age and other information may not be as accurate as offline, face-to-face surveys, and the respondents may be more concerned about lifestyle and dietary nutrition than the general population, and extrapolation of the conclusions of this study to the entire population might be limited. However, these participants who actively interested in this survey are targeted residents of the CHLA Campaign publicity and intervention. The results revealed the weak publicity knowledge points and intervention groups of the CHLA Campaign, and could provide a reference for setting the salt reduction action goal in the future. Second, we analyzed the change of salt-related knowledge and behavior between 2019 and 2020 based on two cross-sectional surveys, but did not follow up with the same participants; changes of participants during the 2-year period cannot be observed. Additionally, the total number of responders in 2020 was much higher than those in 2019, which might be caused by the COVID-19 pandemic, the theme activity of Healthy Lifestyle Promotion Month in early September and the increasing followers of our WeChat public platform, and the sample bias of the comparison results in this study may exist, which would make our study less persuasive. Third, attitude-related questions such as reasons for a reluctance to salt reduction, responsibility for salt reduction and preference of salt-reduction measures, which were often used in previous articles $[21,22,33]$ may be helpful for formulating salt reduction policies and strategies; in this study, we only asked salt-related taste and willingness of reducing the amount of cooking salt in households, which may fail to fully reflect participants' attitudes towards salt reduction and analyze the inner relationship of salt-related Knowledge-Attitude-Practice (KAP). Besides, the self-reported salt related behaviors of participants were not verified by urine assessment of sodium intake; the actual change in the salt intake of these WeChat users was unknown.

\section{Conclusions}

In order to dynamically understand the public's awareness and practice of the salt reduction core information released by the CHLA public platform and to select targeted and effective salt reduction interventions for the CHLA Campaign, a WeChat-based online 
questionnaire was established. The status and changes of salt-related knowledge and behaviors of Chinese WeChat users between 2019 and 2020 were analyzed. Results show that the willingness of reducing the amount of cooking salt in households was very high, but the level of salt-related knowledge decreased and the proportion of salt reduction and high-salt intake behaviors increased from 2019 to 2020, which may due to the potential impact of COVID-19 epidemic. The distribution of salt-related knowledge and behaviors between subgroups was basically indifferent within 2 years. The results also point out that promotion and education of salt-related knowledge and online behavior intervention are still needed, particularly for male and hypertension patients in the future, which will be fully considered in CHLA Campaign salt reduction action. According to the results, the national CHLA office has produced new video materials and standard education series courseware relate to salt reduction and graphic materials on low-salt diet strategies for people with hypertension or cardiovascular diseases. Additionally, we have integrated these existing salt reduction materials and developed a WeChat mini-program for WeChat users' online intervention, which will be used in the next step to promote the national salt reduction action. In addition, we are also adjusting the content and long-term goals of the upcoming salt-reduction action plan based on the survey results. We believe that this WeChat-based survey will provide basic data for the follow-up investigation, which we will definitely continue to conduct, and it might be a useful instrument for other salt-reduction activities.

Supplementary Materials: The following are available online at https:/ /www.mdpi.com/article/10 .3390/nu13072141/s1, Table S1: Main summary of the salt WeChat-based survey.

Author Contributions: Conceptualization, Y.Y., J.M. and W.S.; Formal analysis, Y.Y., J.M. and J.W. (Jing Wu); Investigation, Y.Y., J.W. (Jinglei Wang), J.M. and W.S.; Methodology, Y.Y., J.W. (Jinglei Wang), J.M., W.S. and J.W. (Jing Wu); Writing-original draft, Y.Y., J.W. (Jinglei Wang), W.S. and J.W. (Jing Wu); Writing—review and editing, Y.Y., W.S. and J.W. (Jing Wu). All authors have read and agreed to the published version of the manuscript.

Funding: This research was funded by the China CDC's NCD and tobacco control program (131031001000190010), the China CDC-Resolve Salt Reduction Program (06231) and Salt Reduction Promotion Program (06239).

Institutional Review Board Statement: The online survey was conducted according to the guidelines of the Declaration of Helsinki, and approved by Chinese Center for Disease Control and Prevention Institutional Review Board (No.202108).

Informed Consent Statement: At the front of this WeChat-based survey platform, we set up an "Informed Consent Statement Page" to inform the purpose, content and voluntariness of this online survey to all participants. In this page, we also reminded the participants that "If you continue to participate in the activity, you will be deemed to agree to the informed consent statement".

Data Availability Statement: The data presented in this study are available on request from the corresponding author.

Conflicts of Interest: The authors declare no conflict of interest.

\section{References}

1. Wang, L.H. Non-Communicable and Chronic Diseases Control and Prevention; People's Medical Publishing House: Beijing, China, 2018.

2. Theo, V.; Stephen, S.L.; Cristiana, A.; Kaja, M.A.; Mohammad, A.; Mitra, A.; Mohsen, A.; Hedayat, A.; Foad, A.; Ahmed, A.; et al Global burden of 369 diseases and injuries in 204 countries and territories, 1990-2019: A systematic analysis for the Global Burden of Disease Study 2019. Lancet 2020, 396, 1204-1222.

3. Bureau of Disease Control and Prevention of the National Health and Family Planning Commission. Report on Chinese Resident's Chronic Diseases and Nutrition; People's Medical Publishing House: Beijing, China, 2015.

4. Hu, S.; Gao, R.; Liu, L.; Zhu, M.; Wang, W.; Wang, Y.; Wu, Z.; Li, H.; Gu, D.; Yang, Y.; et al. Summary of the 2018 report on cardiovascular diseases in China. Chin. Circ. J. 2019, 34, 209-220.

5. Mozaarian, D.; Fahimi, S.; Singh, G.M.; Micha, R.; Khatibzadeh, S.; Engell, R.E.; Lim, S.; Danaei, G.; Ezzati, M.; Powles, J.; et al. Global sodium consumption and death from cardiovascular causes. N. Engl. J. Med. 2014, 371, 624-634. [CrossRef] 
6. Aburto, N.J.; Ziolkovska, A.; Hooper, L.; Elliott, P.; Cappuccio, F.P.; Meerpohl, J.J. Effect of lower sodium intake on health: Systematic review and meta-analyses. BMJ 2013, 346, f1326. [CrossRef]

7. He, F.J.; Li, J.; Macgregor, G.A. Effect of longer term modest salt reduction on blood pressure: Cochrane systematic review and meta-analysis of randomised trials. BMJ 2013, 346, f1325. [CrossRef]

8. GBD 2017 Risk Factor Collaborators. Global, regional, and national comparative risk assessment of 84 behavioural, environmental and occupational, and metabolic risks or clusters of risks for 195 countries and territories, 1990-2017: A systematic analysis for the Global Burden of Disease Study 2017. Lancet 2018, 392, 1923-1994.

9. World Health Organization. Salt Reduction. Available online: https://www.who.int/news-room/fact-sheets/detail/saltreduction (accessed on 27 April 2020).

10. The State Council Information Office. The State Council Information Office (SCIO) holds Press Briefing on "Report on the Nutrition and Chronic Disease Status of Chinese Residents 2020". Available online: http:/ /www.gov.cn/xinwen/2020-12/24 / content_5572983.htm (accessed on 27 April 2020).

11. Li, Y.; Zhang, P.; Wu, J.; Ma, J.; Xu, J.; Zhang, X.; Luo, R.; Liu, M.; Sun, Y.; Li, X.; et al. Twenty-Four-Hour Urinary Sodium and Potassium Excretion and Their Associations with Blood Pressure Among Adults in China: Baseline Survey of Action on Salt China. Hypertension 2020, 76, 1580-1588. [CrossRef]

12. World Health Organization. Guideline: Sodium Intake for Adults and Children; WHO: Geneva, Switzerland, 2012.

13. Chinese Nutrition Society. Dietary Guidelines for Chinese Residents 2016; People's Medical Publishing House: Beijing, China, 2016.

14. Shao, S.; Hua, Y.; Yang, Y.; Liu, X.; Fan, J.; Zhang, A.; Xiang, J.; Li, M.; Yan, L.L. Salt reduction in China: A state-of-the-art review. Risk Manag. Healthc. Policy 2017, 10, 17-28. [CrossRef]

15. Xu, A.; Ma, J.; Guo, X.; Wang, L.; Wu, J.; Zhang, J.; Bai, Y.; Xu, J.; Lu, Z.; Xu, Z.; et al. Association of a Province-Wide Intervention With Salt Intake and Hypertension in Shandong Province, China, 2011-2016. JAMA Intern. Med. 2020, 180, 877-886. [CrossRef]

16. He, F.; Wu, Y.; Feng, X.; Ma, J.; Ma, Y.; Wang, H.; Zhang, J.; Yuan, J.; Lin, C.; Caryl, N.; et al. School based education programme to reduce salt intake in children and their families (School-EduSalt): Cluster randomised controlled trial. BMJ 2015, 350, h770. [CrossRef]

17. Li, Y.; Wang, J.; Zhang, X.; Wu, J.; Liang, X. Retrospect and Prospect of Healthy Lifestyle for All, 2007-2015. Chin. J. Health Edu. 2016, 32, 1143-1145.

18. Chinese Center for Disease Control and Prevention. "All Action, Salt Control by All", The First China Salt Reduction Conference Was Successfully Held. Available online: http:/ / www.chinacdc.cn/yw_9324/201908/t20190828_205038.html (accessed on 27 April 2020).

19. Zhang, J.; Astell-Burt, T.; Seo, D.C.; Feng, X.; Kong, L.; Zhao, W.; Li, N.; Li, Y.; Yu, S.; Feng, G.; et al. Multilevel evaluation of "China Healthy Lifestyles for All", a nationwide initiative to promote lower intakes of salt and edible oil. Prev. Med. 2014, 67, 210-215. [CrossRef]

20. Yang, Y.; He, D.; Wei, L.; Wang, S.; Chen, L.; Luo, M.; Mao, Z. Association between diet-related knowledge, attitudes, behaviors, and self-rated health in Chinese adult residents: A population-based study. BMC Public Health 2020, 20, 720. [CrossRef]

21. Bhana, N.; Utter, J.; Eyles, H. Knowledge, Attitudes and Behaviours Related to Dietary Salt Intake in High-Income Countries: A Systematic Review. Curr. Nutr. Rep. 2018, 7, 183-197. [CrossRef]

22. Grimes, C.A.; Khokhar, D.; Bolton, K.A.; Trieu, K.; Potter, J.; Davidson, C.; Dunford, E.K.; Jan, S.; Woodward, M.; Bolam, B.; et al. Salt-Related Knowledge, Attitudes and Behaviors (KABs) among Victorian Adults Following 22-Months of a Consumer Awareness Campaign. Nutrients 2020, 12, 1216. [CrossRef]

23. Patel, D.; Cogswell, M.E.; John, K.; Creel, S.; Ayala, C. Knowledge, Attitudes, and Behaviors Related to Sodium Intake and Reduction Among Adult Consumers in the United States. Am. J. Health Promot. 2017, 31, 68-75. [CrossRef]

24. Ghimire, K.; Adhikari, T.B.; Rijal, A.; Kallestrup, P.; Henry, M.E.; Neupane, D. Knowledge, attitudes, and practices related to salt consumption in Nepal: Findings from the community-based management of non-communicable diseases project in Nepal (COBIN). J. Clin. Hypertens. 2019, 21, 739-748. [CrossRef]

25. Iaccarino, I.P.; D’Elia, L.; Cairella, G.; Sabino, P.; Scalfi, L.; Fabbri, A.; Galletti, F.; Garbagnati, F.; Lionetti, L.; Paolella, G.; et al. Salt and Health: Survey on Knowledge and Salt Intake Related Behaviour in Italy. Nutrients 2020, 12, 279. [CrossRef]

26. Jessen, N.; Santos, A.; Damasceno, A.; Silva-Matos, C.; Severo, M.; Padrao, P.; Lunet, N. Knowledge and behaviors regarding salt intake in Mozambique. Eur. J. Clin. Nutr. 2018, 72, 1690-1699. [CrossRef]

27. Hu, C.; Zhang, M.; Zhang, W.; Zhang, X.; Zhao, Z.; Huang, Z.; Li, C.; Wang, L. Salt-Related Knowledge, Behaviors, and Associated Factors Among Chinese Adults-China, 2015. China CDC Wkly. 2020, 2, 678-683. [CrossRef]

28. Bureau of Disease Control and Prevention of the National Health Commission. Notice on Launching Publicity Activities for the 2019 National Healthy Lifestyle Month. Available online: http:/ / www.jiankang121.cn/NewsDetail.aspx?id=681 (accessed on 27 April 2020).

29. World Health Organization. The " $5 \mathrm{G}$ " Era of Salt Reduction is Coming. Available online: https://baijiahao.baidu.com/s?id=1643 361964880212894\&wfr=spider\&for=pc (accessed on 27 April 2020).

30. Chinese Center for Disease Control and Prevention. Joint Initiative of Promoting the "Reduction of Salt, Oil, and Sugar" in the Food Industry. Available online: http://www.chinacdc.cn/gsywlswxx_9503/bdbs_1/201809/t20180928_194371.html (accessed on 27 April 2020). 
31. Sun, M.; Yang, L.; Chen, W.; Luo, H.; Zheng, K.; Zhang, Y.; Lian, T.; Yang, Y.; Ni, J. Current status of official WeChat accounts for public health education. J. Public Health 2020, 1-7. [CrossRef] [PubMed]

32. Yu, Q.; Xu, L.; Li, L.; Zhi, M.; Gu, Y.; Wang, X.; Guo, H.; Li, Y.; Fan, Y.; Yang, B.; et al. Internet and WeChat used by patients with Crohn's disease in China: A multi-center questionnaire survey. BMC Gastroenterol. 2019, 19, 97. [CrossRef]

33. Chen, S.; Shan, L.C.; Tao, W.; Lu, T.; Regan, A.; Han, H.; Guo, L.; Deng, T.; Wall, P. A survey of Chinese consumers' knowledge, beliefs and behavioural intentions regarding salt intake and salt reduction. Public Health Nutr. 2020, 23, 1450-1459. [CrossRef]

34. Gao, C.; Wang, Z.; Liu, Y.; Lu, Y.; Zhang, X.; Yang, Y. A comprehensive analysis on the range of sodium contents of Chinese various pre-packaged foods. Acta Nutr. Sin. 2017, 39, 217-222.

35. Xi, B.; Hao, Y.; Liu, F. Salt reduction strategies in China. Lancet 2014, 383, 1128. [CrossRef]

36. Zhang, J.; Wu, T.; Chu, H.; Feng, X.; Shi, J.; Zhang, R.; Zhang, Y.; Zhang, J.; Li, N.; Yan, L.; et al. Salt intake belief, knowledge, and behavior: A cross-sectional study of older rural Chinese adults. Medicine 2016, 95, e4404. [CrossRef] [PubMed]

37. Qin, Y.; Li, T.; Lou, P.; Chang, G.; Zhang, P.; Chen, P.; Qiao, C.; Dong, Z. Salt intake, knowledge of salt intake, and blood pressure control in Chinese hypertensive patients. J. Am. Soc. Hypertens. 2014, 8, 909-914. [CrossRef]

38. Zhang, J.; Xu, A.; Shi, X.; Ma, J.; Guo, X.; Lu, Z.; Wang, H.; Li, Y.; Liang, X. The awareness of recommended limit of dietary salt and determinants in Shandong Province, China. Chin. J. Dis. Control. Prev. 2013, 17, 520-524.

39. Dewey, G.; Wickramasekaran, R.N.; Kuo, T.; Robles, B. Does sodium knowledge affect dietary choices and health behaviors? Results from a survey of Los Angeles county residents. Prev. Chronic. Dis. 2017, 14, E120. [CrossRef]

40. Committee for Revision of Chinese Guidelines for the Management of Hypertension. 2018 Chinese guidelines for the management of hypertension. Chin. J. Cardiovasc. Med. 2019, 24, 1-46.

41. Promotional Committee of Healthy China Initiative. Healthy China Initiative (2019-2030). 2019. Available online: http: //www.nhc.gov.cn/guihuaxxs/s3585u/201907/e9275fb95d5b4295be8308415d4cd1b2.shtml (accessed on 27 April 2020).

42. Chen, J.; Tian, Y.; Liao, Y.; Yang, S.; Li, Z.; He, C.; Tu, D.; Sun, X. Salt-restriction-spoon improved the salt intake among residents in China. PLOS ONE 2013, 8, e78963. [CrossRef]

43. Zhang, X.; Hu, X.; Ma, J.; Zhang, P.; Li, Y.; Luo, R.; He, F.J.; MacGregor, G.A.; Wang, J.; Yin, Z. Cluster randomised controlled trial of home cook intervention to reduce salt intake in China: A protocol study. BMJ Open 2020, 10, e033842. [CrossRef] [PubMed]

44. Xu, J.; Yan, L.; Chen, X.; Cai, X.; Jiang, Y.; Wang, L.; Ma, J. Investigation on knowledge, attitude and behavior of salt reduction in Chinese adults, 2010. Chin. J. Prev. Med. 2014, 48, 350-354.

45. Jia, P.; Liu, L.; Xie, X.; Yuan, C.; Chen, H.; Guo, B.; Zhou, J.; Yang, S. Changes in dietary patterns among youths in China during COVID-19 epidemic: The COVID-19 impact on lifestyle change survey (COINLICS). Appetite 2021, 158, 105015. [CrossRef]

46. Yang, G.Y.; Lin, X.L.; Fang, A.P.; Zhu, H.L. Eating Habits and Lifestyles during the Initial Stage of the COVID-19 Lockdown in China: A Cross-Sectional Study. Nutrients 2021, 13, 970. [CrossRef] [PubMed]

47. Zhang, J.; Zhao, A.; Ke, Y.; Huo, S.; Ma, Y.; Zhang, Y.; Ren, Z.; Li, Z.; Liu, K. Dietary Behaviors in the Post-Lockdown Period and Its Effects on Dietary Diversity: The Second Stage of a Nutrition Survey in a Longitudinal Chinese Study in the COVID-19 Era. Nutrients 2020, 12, 3269. [CrossRef] [PubMed]

48. McKenzie, B.; Santos, J.A.; Trieu, K.; Thout, S.R.; Johnson, C.; Arcand, J.; Webster, J.; McLean, R. The Science of Salt: A focused review on salt-related knowledge, attitudes and behaviors, and gender differences. J. Clin. Hypertens. 2018, 20, 850-866. [CrossRef] [PubMed] 